\title{
PEMANFAATAN LIMBAH UBI KAYU DARI SISA PENGOLAHAN TEPUNG TAPIOKA DI KECAMATAN MARGOYOSO KABUPATEN PATI MENJADI BAHAN ADSORBEN UNTUK PENJERNIH AIR
}

\author{
Jotti Karunawan ${ }^{\text {a) }}$, Annisa Lidia Wati ${ }^{\text {b) }}$, Ita Rahmawati ${ }^{\text {c) }}$, Aan Priyanto ${ }^{\text {d) }}$, Sulhadie), \\ Mahardika Prasetya Aji ${ }^{\mathrm{f}}$ \\ Jurusan Fisika, Fakultas Matematika dan Ilmu Pengetahuan Alam, Universitas Negeri Semarang \\ Jalan Raya Sekaran Gunungpati, Semarang, Jawa Tengah 50229 \\ Email: a)jottikarunawan@gmail.com, b)annisalidiawati@gmail.com, ${ }^{c}$ ittarahma25@ gmail.com, \\ d) priyantoaan22@gmail.com, ${ }^{\mathrm{e})}$ sulhadipati@yahoo.com, ${ }^{\text {f) }}$ mahardika190@gmail.com
}

\begin{abstract}
Abstrak
Sentra produksi ubi kayu di Provinsi Jawa Tengah dihasilkan oleh daerah Kabupaten Pati. Tingginya produksi ubi kayu didukung dengan pengolahan pasca panen yaitu pengolahan ubi kayu menjadi tepung tapioka. Namun permasalahan yang muncul adalah limbah dari sisa pengolahan ubi kayu menjadi tepung tapioka belum dapat dimanfaatkan secara keseluruhan sehingga dapat mencemari lingkungan. Melalui proses pirolisis limbah ubi kayu dihasilkan arang (bahan karbon). Uji kinerja karbon yang dihasilkan dari limbah ubi kayu digunakan sebagai adsorben pada limbah tekstil methylene blue. Hasil uji kinerja menunjukan bahwa intensitas absorbsi methylene blue menurun. Hal ini mengindikasikan adanya proses absorbsi methylene blue oleh karbon. Laju penurunan intensitas absorbsi methylene blue semakin cepat dengan penambahan massa karbon. Karbon dari limbah ubi kayu sisa pengolahan tepung tapioka dapat efektif sebagai adsorben untuk mereduksi limbah tekstil methylene blue.
\end{abstract}

Kata-kata kunci: limbah, ubi kayu, kabupaten pati.

\begin{abstract}
One of the central cassava production is located in Pati Regency Central Java. The high production of cassava is supported by cassava post-harvest and process it into tapioca flour. However, the problem arises during the production of tapioca flour from cassava. Waste materials which are produced from tapioca flour production pollute the environment. Charcoal (carbon material) has been produced from tapioca waste material production through pyrolysis process. The carbon performance is tested by analyzing its absorbance toward methylene blue solutions. The carbon performance testing shows that the absorption intensity of methylene blue decreased. This result indicates the absorption of methylene blue by carbon. The descent rate of methylene blue intensity is correspond to tho the addition of carbon mass. Carbon from cassava waste is effective as absorbent to reduce methylene blue textile waste.
\end{abstract}

Keywords: Waste, Cassava, Pati district. 


\section{PENDAHULUAN}

Salah satu sentra produksi ubi kayu atau singkong di Provinsi Jawa Tengah terletak di Kabupaten Pati. Dengan luas area tanamannya 20 ribu ha dan rata-rata produktivitasnya mencapai 35 ton per ha, kontribusi Kabupaten Pati dalam produksi ubi kayu nasional sekitar 700 ribu ton (umbi basah) pada tahun 2016 [1]. Tingginya produksi ubi kayu di Kabupaten Pati tak luput dari minat petani yang begitu besar untuk mengembangkannya. Tingkat keuntungan yang memadai, berkembangnya industri olahan berbahan baku ubi kayu, serta didukung oleh kesesuaian lahan dan pola tanam yang teratur.

Tingginya produksi ubi kayu didukung dengan pengolahan pasca panen yaitu pengolahan ubi kayu menjadi tepung tapioka. Di Kecamatan Margoyoso terdapat kurang lebih 400 UKM yang tersebar di tiga desa, yaitu Desa Ngemplak kidul, Desa Sidomukti dan Desa Ngemplak lor.

Proses pembuatan tepung tapioka pada umumnya terdiri dari tiga tahapan, yaitu pengupasan kulit singkong, penghalusan daging singkong yang telah dikupas, serta pemerasan dan penyaringan parutan singkong yang telah tercampur air. Tepung tapioka itu sendiri merupakan sari dari endapan hasil proses pemerasan dan penyaringan. Panjangnya proses pembuatan tepung tapioka ini menimbulkan banyak polutan antara lain kulit singkong, ampas serta limbah cair hasil pemrosesan. Polutan cair langsung dibuang ke sungai dan selokan-selokan sedangkan polutan padat dimanfaatkan sebagai pakan ternak dan selebihnya dibuang karena mengandung Cyanogenic glucosides yang dapat meracuni hewan ternak. Polutan cair maupun padat ini memberikan dampak lingkungan berupa pencemaran sungai dan bau yang kurang sedap. Banyaknya polutan yang dihasilkan dipandang perlu dilakukan upaya pemanfaatan dan pengolahan sehingga menjadi bahan yang bernilai guna.

Beberapa solusi telah ditawarkan untuk mengurangi polutan padat hasil pengolahan tepung tapioka, salah satunya dengan mendaur kulit singkong menjadi karbon [2]. Karbon merupakan padatan amorf berbentuk heksagonal berwarna warna hitam hasil dari pembakaran dengan oksigen rendah (pyrolysis) [3]. Karbon memiliki sifat absorbsi dan kestabilan termal yang sangat baik sehingga digunakan sebagai elektroda pada perangkat elektrokimia [4]. Keunggulan sifat absorbsi ini menjadikan karbon banyak digunakan sebagai medium filter untuk berbagai macam polutan [5].

Keunggulan sifat absorbsi dari material karbon memungkinkan pemanfaatan kulit singkong sebagai media absorbsi polutan cair dari proses pembuatan tepung tapioka. Pembuatan karbon dari sisa pengolahan tepung tapioka yang murah memungkinkan kegiatan daur ulang ini dapat dilakukan. Karbon merupakan material yang tidak beracun. Sehingga selain akan mengurangi polutan padat kulit singkong, polutan cair dapat diarbsorbsi karbon sehingga air dapat digunakan kembali. Hal ini memberikan harapan manfaat selain pengurangan limbah juga mengurangi biaya produksi industri. Penelitian ini berfokus pada pembuatan karbon aktif dari kulit singkong dan tingkat efektifitas karbon aktif untuk absorbsi polutan cair limbah industri pengolahan tepung tapioka. Hasil dari penelitian ini diharapkan bermanfaat bagi pelaku industri pengolahan tepung tapioka dan sebagai upaya penanggulangan masalah limbah industri tepung tapioka di Kabupaten Pati.

\section{METODE PENELITIAN}

Bahan yang digunakan untuk membuat karbon sebagai adsorben adalah sisa pengolahan tepung tapioka berupa ampas ubi kayu.

\section{Proses Karbonisasi}

Pembuatan karbon dari ampas ubi kayu dilakukan dengan menggunakan drum besi yang dilubangi bagian bawah untuk pembakaran. Ampas ubi kering dibakar dalam keadaan oksigen rendah (pirolisis). Tujuan dari pembakaran oksigen rendah supaya bahan organik dapat terdekomposisi secara maksimal sehingga menghasilkan residu berupa karbon. 


\section{Proses Penghalusan Karbon}

Karbon dari proses karbonisasi dihaluskan menggunakan lumpang porselin sampai dihasilkan karbon yang halus. Kemudian disaring menggunakan ayakan 90 mesh agar ukurannya homogen.

\section{Proses Pengujian Karbon pada Methylene Blue}

Pengujian pada limbah methylene blue dilakukan pada kadar methylene blue 20 ppm. Perlakuan yang diberikan dengan memvariasi waktu kontak antara karbon ampas ubi kayu dengan methylene blue $(100 \mathrm{~mL})$. variasi waktu kontak yaitu 30 menit, 60 menit, 90 menit, dan 120 menit sedangkan kabon yang diberikan konstan yaitu 0,1 gram.

\section{HASIL DAN PEMBAHASAN}

Penelitian ini bertujuan untuk mengadsorbsi methylene blue di dalam air dengan menggunakan karbon berbahan dasar limbah ubi kayu. Proses pembuatan karbon menggunakan metode pirolisis sederhana. Dalam penelitian ini, kadar methylene blue yang digunakan yaitu $20 \mathrm{ppm}$ dan proses adsorbsi dilakukan dengan memvariasikan waktu kontak antara karbon dengan methylene blue. Adapun variasi waktu yang digunakan adalah 0 menit, 30 menit, 60 menit, 90 menit dan 120 menit. Gambar 1 merupakan hasil dari proses adsorbsi dengan menggunakan karbon.

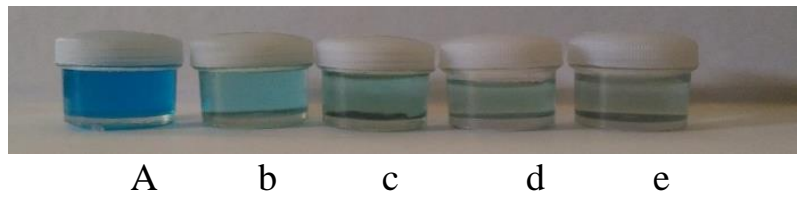

Gambar 1. Hasil proses adsorbsi dengan menggunakan karbon (a) 0 menit, (b) 30 menit, (c) 60 menit, (d) 90 menit dan (e) 120 menit

Dari gambar 1 menunjukkan bahwa semakin lama waktu kontak antara karbon dengan methylene blue maka warna yang dihasilkan juga semakin jernih. Hal ini membuktikan bahwa karbon berbahan dasar limbah ubi kayu efektif digunakan sebagai adsorben untuk penjernih air. Tingkat adsorbsi karbon diestimasi melalui spektrum absorbansi. Berdasarkan spektrum absorbansi apabila daerah serapan dari suatu larutan semakin kecil maka jumlah partikel yang terlarut semakin berkurang. Berkurangnya jumlah partikel mengakibatkan larutan tersebut semakin jernih.

Spektrum absorbansi diperoleh berdasarkan analisis sifat optik dari methylene blue yang telah teradsorbsi oleh karbon. Analisis ini menggunakan spektrofotometer UV-VIS-Nir. Gambar 2 menunjukkan hasil adsorbsi karbon pada larutan methylene blue. 


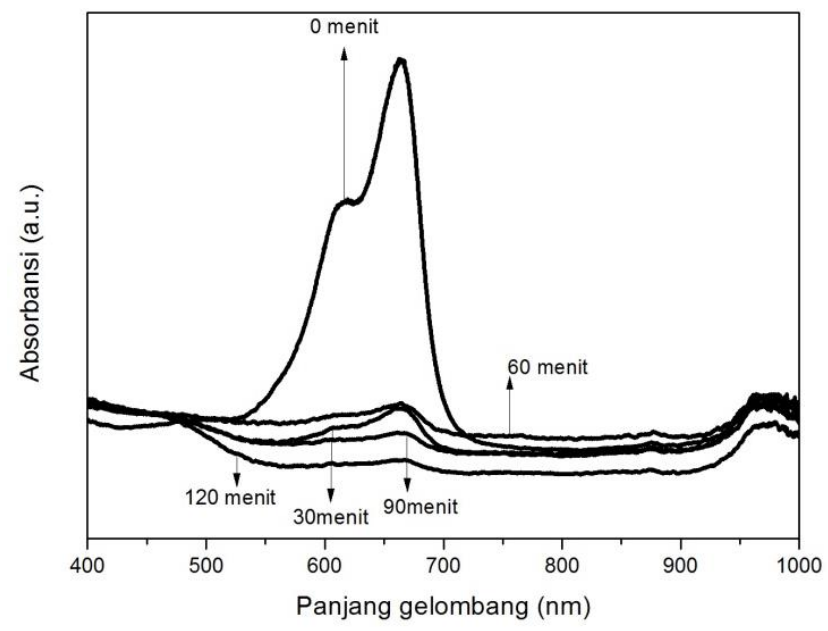

Gambar 2. Spektrum absorbansi methylene blue dengan variasi lama waktu kontak

Gambar 2 menunjukkan bahwa methylene blue merespon cahaya pada panjang gelombang 500$700 \mathrm{~nm}$. Absorbansi methylene blue tanpa perlakuan kontak dengan karbon mempunyai puncak serapan tertinggi yaitu berada pada panjang gelombang $~ 665 \mathrm{~nm}$. Absorbansi semakin menurun seiring dengan lama waktu kontak antara methylene blue dengan karbon yang diberikan. Menurunnya absorbansi ini karena konsentrasi methylene blue di dalam air semakin menurun. Hal ini sesuai dengan hukum LambertBeer yang menyatakan bahwa besarnya absorbansi sebanding dengan konsentrasi zat yang terkandung. Hubungan antara absorbansi dengan konsentrasi ini ditunjukkan oleh persamaan (1) dan (2).
$I_{\mathrm{t}}=I_{0} e^{- \text {(atc) }}$
$\log \frac{I_{0}}{I_{t}}=a l C=A$

Dengan $\alpha$ adalah koefisien absorbsi, $l$ adalah panjang lintasan, $A$ adalah absorbansi, $I_{o}$ dan $I_{t}$ adalah intensitas cahaya mula-mula dan intensitas cahaya transmisi.

Penurunan konsentrasi methylene blue disebabkan adanya penyerapan partikel methylene blue ke dalam karbon. Semakin lama waktu yang digunakan untuk mengontakkan karbon dengan methylene blue maka semakin banyak pula partikel methylene blue yang masuk ke dalam pori karbon.

Berdasarkan gambar 2, waktu kontak selama 120 menit menunjukkan absorbansi methylene blue mendekati 0 . Hal ini mengindikasikan bahwa pada waktu 120 menit, karbon limbah ubi kayu menyerap methylene blue di dalam air sepenuhnya. Dengan demikian dapat dikatakan bahwa waktu 120 menit merupakan waktu optimum penyerapan methylene blue oleh karbon berbahan dasar limbah ubi kayu.

\section{SIMPULAN}

Limbah ubi kayu dari sisa pengolahan tepung tapioka di Kecamatan Margoyoso Kabupaten Pati efektif menjadi bahan adsorben untuk penjernih air dengan lama waktu kontak optimal 120 menit.

\section{UCAPAN TERIMAKASIH}

Penelitian ini didukung dengan pendanaan PNBP DIPA MIPA Universitas Negeri Semarang Tahun 2017. 


\section{REFERENSI}

[1] R. Widaningsih. "Outlook Komoditas Pertanian Sub Sektor Tanaman Pangan Ubi Kayu”. Pusat data dan Sistem Informasi Pertanian. Kementerian Pertanian. Jakarta. ISSN 1907-1507. Oktober. 2016.

[2] Ikawati dan Melati. "Pembuatan Karbon Aktif dari Limbah Kulit Singkong UKM Tapioka Kabupaten Pati”. Skripsi. Universitas Diponegoro. 2010.

[3] D. S. Wijayanti. "Karakteristik Briket Arang dari Serbuk Gergaji dengan Penambahan Arang Cangkang Kelapa Sawit”. Skripsi. Universitas Sumatera Utara. 2009.

[4] O. S. Amuda et al., "Adsorption of Methylene Blue from Aqueous Solution Using SteamActivated Carbon Produced From Lantana camara Stem". Journal of Environmental Protection 5: 1352-1363. 2014.

[5] N. U. Ahmad et al., "Adsorption of Methylene Blue in Aqueous Solution by Musa Paradisiaca Stem Powder". ARPN Journal of Engineering and Applied Science 11 (9): 6186-6190. 2016.

[6] F. Via and T. Siti., "Pembuatan dan Karakterisasi Karbon Aktif dari Tempurung Keluwak (Pangium Edule) dengan Aktivator $\mathrm{H}_{3} \mathrm{PO}_{4}$ ". Prosiding Seminar Nasioal dan Pembelajarannya. 2016.

[7] Lawal, A. O., et al., "Removal of Methylene Blue Dye and Lead from Water by Active Carbon from Mixed Sorghum and Millet Straws". American Journal of Chemistry 6 (5): 111-118. 2016.

[8] Syauqiah Isna et al., "Analisis Variasi Waktu dan Kecepatan Pengaduk Pada Proses Adsorbsi Limbah Logam Berat dengan Arang Aktif”. Info Teknik 12 (1): 11-20. 2011. 
